\title{
Cholinergic Receptor Mutants of the Nematode Caenorhabditis elegans
}

\author{
James A. Lewis, James S. Elmer, Jeffrey Skimming, Sharon McLafferty, John Fleming, and Thomas McGee \\ Department of Biological Sciences, University of Missouri, Columbia, Missouri 65211
}

\begin{abstract}
Potential acetylcholine receptor (AChR) mutants of the nematode are selectable by resistance to the neurotoxic drug levamisole, a probable cholinergic agonist. To determine which mutants may have achieved resistance through loss of levamisole receptor function, we have assayed mutant extracts for speciflc ${ }^{3} \mathrm{H}-$ meta-aminolevamisole binding activity in the presence and absence of mecamylamine. We find that mutants in 3 of the 7 genes associated with extreme levamisole resistance are obviously deficient in saturable specific ${ }^{3} \mathrm{H}$-meta-aminolevamisole binding activity. Mutants of the 4 other genes have abnormal binding activities that fail to undergo the apparent allosteric activation of saturable specific ${ }^{3} \mathrm{H}$-meta-aminolevamisole binding activity caused by mecamylamine. Thus, all 7 genes appear to be required to produce a fully functional levamisole receptor. Mutants of several other genes associated only with partial resistance to levamisole have at least grossly normal receptor binding activities.
\end{abstract}

Considerable progress is being made towards identifying the structural components of vertebrate neuroreceptors and defining the functions of these components. Large areas of uncerlainty are likely to remain, however, as to what other molecules are involved in the developmental control and expression of these receptors beyond their immediate structural components. A more complete picture of the genes necessary for receptor expression might actually be obtainable by studying an invertebrate like the nematode Caenorhabditis elegans, where the advantages of more modern molecular techniques might be combined with the possibility of identifying genes affecting receptor expression by more classical techniques of mutant selection.

Potential receptor mutants of $C$. elegans can be identified by selection for resistance to the toxic muscle-hypercontracting effects of the nicotine-like drug levamisole (Lewis et al., 1980b). Recent electrophysiological experiments on the larger nematode Ascaris indicate that levamisole acts directly on cholinergic receptors present on nematode muscle (Harrow and Gration, 1985). Loss of muscle receptor function or deficiency in processes further along in the pathway of muscle contraction could allow mutants to escape the overstimulating effects of levamisole. Resistant mutants do arise by mutation of any one of 12 different

Received Aug. 19, 1986; revised May 1, 1987; accepted May 5, 1987.

This investigation has been aided by DHHS Grant GM 31659. Our most sincere thanks to R. L. Russell for making the pursuit of this work possible.

Correspondence should be addressed to Dr. James A. Lewis, Dept. of Biological

Sciences, 110 Tucker Hall, University of Missouri, Columbia, MO 65211.

Abbreviation: MAL, meta-aminolcvamisole.

Copyright @ 1987 Society for Neuroscience $0270-6474 / 87 / 103059-13 \$ 02.00 / 0$ genes, and the mutants fall into 3 different classes (Brenner, 1974; Lewis et al., 1980a). First, mutants that are extremely levamisole-resistant and are receptor-abnormal, as this work will show, occur by mutation of any one of 7 genes. Such mutants share the same stereotyped uncoordinated motor behavior and have increased resistance to cholinergic agonists, but are normal in response to the noncholinergic muscle agonist ouabain. The mutants are very uncoordinated early in larval life, but recover substantially during the time period when new motor neurons and synapses are added to the motor nervous system. The mutants have little or no response to nicotine, to the normally very potent nicotinic cholinergic agonist dimethylphenylpiperazinium, or to the nicotine-like anthelmintics levamisole and pyrantel, but still have a noticeable, although reduced, response to the more direct acetylcholine analog carbachol. The phenotype of these extremely levamisole-resistant mutants is consistent with a deficiency of a juvenile nicotinic acetylcholine receptor type and with the continued independent existence of other non-nicotinic acetylcholine receptor (AChR) types in the nematode.

A second class of mutants has much weaker resistance to levamisole and cholinergic agonists and appears normal in motor behavior. Some mutants in this class simply represent mutations of weaker effect in some of the 7 genes also mutable to extreme levamisole resistance. Three additional genes are identifiable only as genes giving rise to partial resistance. Extremely resistant mutant isolates of these genes have never been found.

A third class of mutants arises from mutation of either of 2 genes. Mutants of this class exhibit spasmodic muscle twitching and have partial resistance to levamisole and cholinergic agonists, as well as resistance to the noncholinergic muscle agonist ouabain. Consequently, these mutants probably represent defects in muscle contraction physiologically downstream from the site of levamisole action.

To characterize the receptor present in these 3 classes of levamisole-resistant mutants, we have developed a tritiated ligand binding assay. We synthesized tritiated meta-aminolevamisole ( $\left.{ }^{3} \mathrm{H}-\mathrm{MAL}\right)$, a much morc potent derivative of the mutant-selective agent levamisole (Lewis and Paterson, 1984). Using ${ }^{3} \mathrm{H}-$ MAL, a high-affinity binding activity can be detected in extracts of the wild-type nematode (Lewis et al., 1987). Binding is competed by levamisole derivatives and cholinergic agonists with the same relative potencies that these compounds exhibit in causing nematode muscle contraction. The pharmacological specificity of the nematode receptor is different from that of any other cholinergic receptor described so far. Vertebrate cholinergic antagonists do not inhibit ligand binding, but mecamylamine and the snake neurotoxins $\alpha$-bungarotoxin and cobra 


\section{Table 1. Mutant strains used}

Extremely resistant uncs

ZZ13 lev-7 $(\times 13)$

ZZ18 unc-63( $\times 18)$

ZZ19 unc-74 $(\times 19)$

ZZ20 unc-38 $(\times 20)$

ZZ21 lev- $1(\times 21)$

ZZ28 unc-38( $\times 28)$

ZZ29 unc $-29(\times 29)$

ZZ36 unc-29( $\times 36)$

ZZ37 unc-63( $\times 37)$

ZZ47 unc-50 $\times 47)$

ZZ55 unc-74( $\times 55)$

ZZ61 lev- $I(\times 61)$

CB306 unc-50(e306)
Partially resistant mutants with wild-type motor behavior

ZZ15 lev-8(×15)

ZZ16 lev-9(×16)

$\mathrm{ZZ17} \quad \mathrm{lev}-10(\times 17)$

$\mathrm{ZZ22}$ lev- $1(\times 22)$

$\mathrm{ZZ38} \quad$ lev- $1(\times 38)$

ZZ1006 lev-1( $\times 21)$

$\times 1006 r t$

ZZ1010 lev-l(×6l)

$$
\times 1010 \mathrm{rt}
$$

Partially resistant twitcher mutants

$\mathrm{ZZ12}$ lev-11( $\times 12)$

CB66 unc-22(e66)

Uncoordinated mutant sensitive to levamisole

ZZ14 unc-68 $(\times 14)$

$r t$, Revertant.

Naja naja kaouthia venom cause allosteric activation of ${ }^{3} \mathrm{H}-$ MAL binding. The noncompetitive blocking effect of mecamylamine obscrved in vivo might be thus explained if the higher affinity ${ }^{3} \mathrm{H}-\mathrm{MAL}$ binding state produced by mecamylamine were a physiologically inactive state of the receptor. Similar activation of cholinergic ligand binding by noncompetitive blocking agents has been observed for the vertebrate nicotinic skeletal AChR (discussed by Changeux et al., 1983).

In this work we examine the binding activity arising from alleles of all 12 levamisole resistance loci. Our results indicate that, at the molecular level of ${ }^{3} \mathrm{H}-\mathrm{MAL}$ binding, mutants of all 7 genes associated with extreme levamisole resistance produce an abnormal receptor. Mutants of the 5 other partially resistant loci have grossly normal receptor activity, except for mutants of the 2 twitcher loci, which have about 2 times as much total binding activity as does the wild type.

\section{Materials and Methods}

Materials. All materials used were as previously described (Lewis et al., 1987).

Strains and culture conditions. The wild-type strain of nematode was the Bristol variety of Caenorhabditis elegans (N2) described by Brenner (1974). The mutants described in this paper are shown in Table 1 and were isolated by us (Lewis et al., 1980a), except that CB306 and CB66 were obtained from the MRC Laboratory of Molecular Biology in Cambridge, England.

Worms were grown and harvested and extracts were prepared as previously described (Lewis et al., 1987). "Well-fed" worms were harvested shortly after all bacteria in the culture flask were consumed, and the worms were purified by centrifugation through $15 \%$, then $35 \%$ (wt/ vol) Ficoll 400, followed by washing. For later experiments, mixtures of dauer larvae and starved juveniles were harvested after 1 week of starvation by flotation through $30 \%$ (wt/vol) sucrose, followed by pelleting through $15 \%(\mathrm{wt} / \mathrm{vol})$ Ficoll 400 and washing. All extracts prepared were frozen and thawed 5 times, using liquid nitrogen to elicit maximal specific ${ }^{3} \mathrm{H}-\mathrm{MAL}$ binding (Lewis et al., 1987).

Binding assay. Determination of mean specific ${ }^{3} \mathrm{H}-\mathrm{MAL}$ binding was done in quadruplicate, as previously described (Lewis et al., 1987). For the assay of well-fed worm extracts, $10 \mu \mathrm{M}$ unlabeled MAL was used as the competitor in the determination of nonspecific binding, and assays were incubated for 60 to $240 \mathrm{~min}$ on ice as necessary to achieve equilibrium. For the assay of starved worm extracts, $0.5 \mathrm{~mm}$ dimethylphenylpiperazinium was used as the unlabeled competitor and all assays were incubated for $240 \mathrm{~min}$ on ice. Total and nonspecific binding in the presence of $1 \mathrm{~mm}$ mecamylamine were determined by including in the $10 \mu l$ assay aliquot reserved for drug additions (Lewis et al., 1987) either $10^{-2} \mathrm{M}$ mecamylamine hydrochloride or $10^{-2} \mathrm{M}$ mecamylamine hydrochloride and the unlabeled competitor, respectively. For well-fed worm extracts, measurements of mean specific ${ }^{3} \mathrm{H}-\mathrm{MAL}$ binding for each extract were normalized to the AChE activity of that extract to correct for any differences in specific ${ }^{7} \mathrm{H}-\mathrm{MAL}$ binding between extracts that might be caused by differences in the relative age distributions of the mixed-age worm populations used to make the extracts (Lewis et al., 1987). AChE activity was measured at $1 \mathrm{~mm}$ acetylthiocholine chloride, as described by Ellman et al. (1961). We define 1 unit of cholinesterase activity as a change of $1 \times 10^{-3} \mathrm{~A}_{412} \mathrm{U} / \mathrm{sec}$ at $22^{\circ} \mathrm{C}$ in $0.025 \mathrm{M}$ sodium phosphate buffer, $\mathrm{pH}$ 7.0. Protein was measured by the Lowry method as modified by Dulley and Grieve (1975).

Regression analysis of binding measurements. Measurements of mean specific ${ }^{3} \mathrm{H}-\mathrm{MAL}$ binding were fitted to a model of binding activity by weighted nonlinear regression using the SAS program NLIN (SAS Institute, 1985). The theoretical curves generated for the directly observed binding data were simply replotted to obtain the theoretical curves for the Scatchard plots shown. The directly observed binding activity was fitted either to a hyperbola and linc modcl (saturable and nonsaturable activity) or a 2 -hyperbola model (2 saturable activities). Weights for regression were based on the variance for individual mean determi-

Table 2. Binding activity of the wild type and levamisole-resistant mutants grown as well-fed worms

\begin{tabular}{|c|c|c|c|c|c|c|}
\hline Strain & Mec. & $\begin{array}{l}\text { Total saturable } \\
\text { (fmol/mg/AChE) }\end{array}$ & $\begin{array}{l}\text { Dissociation } \\
\text { constant } \\
\text { (nM) }\end{array}$ & $\begin{array}{l}\text { Slope of } \\
\text { nonsaturable } \\
(\mathrm{fmol} / \mathrm{mg} / \mathrm{nm} \\
\left.\mathrm{AChE} \times 10^{-2}\right)\end{array}$ & $\begin{array}{l}\text { No. } \\
\text { pts. } \\
\text { used }\end{array}$ & $\begin{array}{l}\mathrm{AChE} \\
\text { units }\end{array}$ \\
\hline \multirow[t]{2}{*}{ 1. N2, wild type } & - & $1.2 \pm 0.2$ & $5.7 \pm 1.2$ & $1.8 \pm 0.4$ & 11 & 1.79 \\
\hline & + & $1.9 \pm 0.2$ & $1.1 \pm 0.2$ & $2.1 \pm 0.5$ & 15 & \\
\hline \multicolumn{7}{|c|}{ Mutants with low saturable activity } \\
\hline \multirow[t]{2}{*}{ 2. $u n c-29(\times 29)$} & - & $0.1 \pm 0.2$ & ND & $1.0 \pm 0.4$ & 9 & 1.29 \\
\hline & + & $0.08 \pm 0.04$ & ND & $0.9 \pm 0.1$ & 9 & \\
\hline \multirow[t]{2}{*}{ 3. unc- $29(\times 36)$} & - & $0.06 \pm 0.02$ & ND & $0.9 \pm 0.1$ & 9 & 1.99 \\
\hline & + & $0.1 \pm 0.1$ & ND & $0.4 \pm 0.4$ & 9 & \\
\hline \multirow[t]{2}{*}{ 4. $u n c-50(\times 47)$} & - & $0.01 \pm 0.02$ & ND & $1.3 \pm 1.6$ & 11 & 1.47 \\
\hline & + & - & - & $1.2 \pm 0.2^{a}$ & 9 & \\
\hline \multirow[t]{2}{*}{ 5. unc-50(e306) } & - & $0 \pm 0.06$ & ND & $1.5 \pm 0.2$ & 9 & 2.87 \\
\hline & + & $0.02 \pm 0.003$ & ND & $0.7 \pm 0.03$ & 9 & \\
\hline
\end{tabular}


Table 2. Continued

\begin{tabular}{|c|c|c|c|c|c|c|}
\hline$\underline{\text { Strain }}$ & Mec. & $\begin{array}{l}\text { Total saturable } \\
\text { (fmol/mg/AChE) }\end{array}$ & $\begin{array}{l}\text { Dissociation } \\
\text { constant } \\
\text { (nM) }\end{array}$ & $\begin{array}{l}\text { Slope of } \\
\text { nonsaturable } \\
(\mathrm{fmol} / \mathrm{mg} / \mathrm{nM} \\
\left.\mathrm{AChE} \times 10^{-2}\right)\end{array}$ & $\begin{array}{l}\text { No. } \\
\text { pts. } \\
\text { used }\end{array}$ & $\begin{array}{l}\text { AChE } \\
\text { units }\end{array}$ \\
\hline \multirow{2}{*}{ 6. $u n c-74(\times 19)$} & - & $0.04 \pm 0.05$ & ND & $1.2 \pm 0.2$ & 9 & 1.79 \\
\hline & + & $0.2 \pm 0.1$ & ND & $0.6 \pm 0.2$ & 9 & \\
\hline \multirow[t]{2}{*}{ 7. $u n c-74(\times 55)$} & - & - & - & $1.7 \pm 0.2^{a}$ & 10 & 0.89 \\
\hline & + & - & - & $1.4 \pm 0.2^{a}$ & 9 & \\
\hline \multicolumn{7}{|c|}{ Mutants with saturable activity of abnormally high affinity } \\
\hline \multirow[t]{2}{*}{ 8. unc-38( $\times 20)$} & - & $0.6 \pm 0.1$ & $1.2 \pm 0.4$ & $0.2 \pm 0.3$ & 5 & 1.40 \\
\hline & + & $0.7 \pm 0.1$ & $1.2 \pm 0.6$ & $1.0 \pm 0.4$ & 10 & \\
\hline \multirow[t]{2}{*}{ 9. $u n c-38(\times 28)$} & - & $0.8 \pm 0.03$ & $0.9 \pm 0.1$ & $1.1 \pm 0.1$ & 10 & 2.22 \\
\hline & + & $0.9 \pm 0.05$ & $1.4 \pm 0.2$ & $0.9 \pm 0.1$ & 9 & \\
\hline \multirow[t]{2}{*}{ 10. $u n c-63(\times 18)$} & - & $1.0 \pm 0.1$ & $0.5 \pm 0.2$ & $1.1 \pm 0.3$ & 11 & 1.18 \\
\hline & + & $1.2 \pm 0.1$ & $1.1 \pm 0.3$ & $1.4 \pm 0.4$ & 11 & \\
\hline \multirow[t]{2}{*}{ 11. unc- $63(\times 37)$} & - & $1.4 \pm 0.1$ & $1.1 \pm 0.2$ & $1.6 \pm 0.3$ & 12 & 1.39 \\
\hline & + & $1.6 \perp 0.1$ & $1.5 \pm 0.1$ & $0.9 \pm 0.3$ & 9 & \\
\hline \multirow[t]{2}{*}{ 12. $\operatorname{lev}-7(\times 13)$} & - & $0.6 \pm 0.1$ & $0.9 \pm 0.4$ & $1.9 \pm 0.4$ & 9 & 1.55 \\
\hline & + & $0.5 \pm 0.04$ & $0.9 \pm 0.2$ & $1.1 \pm 0.2$ & 9 & \\
\hline \multicolumn{7}{|c|}{ Mutants associated with the $l e v-1$ locus } \\
\hline \multirow[t]{2}{*}{ 13. $l e v-1(\times 6 I)$} & - & $2.5 \pm 0.1$ & $2.0 \pm 0.2$ & $2.4 \pm 0.4$ & 16 & 2.62 \\
\hline & + & $2.7 \pm 0.1$ & $0.9 \pm 0.1$ & $1.7 \pm 0.5$ & 15 & \\
\hline \multirow[t]{2}{*}{ 14. $l e v-I(\times 2 I)$} & - & $2.2 \pm 0.3$ & $4.2 \pm 0.7$ & $4.6 \pm 0.7$ & 9 & 1.42 \\
\hline & + & $3.7 \pm 0.2$ & $2.4 \pm 0.2$ & $3.4 \pm 0.8$ & 9 & \\
\hline \multirow[t]{2}{*}{ 15. $l e v-I(\times 22)$} & - & $1.2 \pm 0.4$ & $10.7 \pm 3.9$ & $1.9 \pm 0.5$ & 8 & 2.09 \\
\hline & + & $1.8 \pm 0.2$ & $8.6 \pm 0.9$ & $1.8 \pm 0.3$ & 9 & \\
\hline \multirow[t]{2}{*}{ 16. $l e v-1(\times 38)$} & - & $1.2 \pm 0.1$ & $0.8 \pm 0.1$ & $1.0 \pm 0.3$ & 9 & 1.78 \\
\hline & + & $1.3 \pm 0.1$ & $0.6 \pm 0.2$ & $1.9 \pm 0.3$ & 9 & \\
\hline \multirow[t]{2}{*}{ 17. ZZ1006 } & - & $1.2 \pm 0.1$ & $5.0 \pm 0.8$ & $1.9 \pm 0.2$ & 9 & 2.89 \\
\hline & + & $1.0 \pm 0.1$ & $5.3 \pm 0.7$ & $2.0 \pm 0.1$ & 9 & \\
\hline \multirow[t]{2}{*}{ 18. $\angle 2 \angle 1010$} & - & $0.8 \pm 0.2$ & $5.4 \pm 1.8$ & $0.8 \pm 0.3$ & 9 & 2.54 \\
\hline & + & $0.9 \pm 0.1$ & $3.6 \pm 0.6$ & $0.5 \pm 0.2$ & 18 & \\
\hline \multicolumn{7}{|c|}{ Partially resistant mutants with nearly wild-type motor behavior } \\
\hline \multirow[t]{2}{*}{ 19. $\operatorname{lev}-8(\times 15)$} & - & $2.1 \pm 0.2$ & $4.0 \pm 0.8$ & $1.4 \pm 0.4$ & 9 & 1.93 \\
\hline & + & $3.2 \pm 0.1$ & $1.4 \pm 0.1$ & $2.7 \pm 0.5$ & 11 & \\
\hline \multirow[t]{2}{*}{ 20. $\operatorname{lev}-9(\times 16)$} & - & $1.1 \pm 0.2$ & $2.2 \pm 0.7$ & $1.6 \pm 0.4$ & 9 & 2.18 \\
\hline & + & $2.2 \pm 0.2$ & $1.7 \pm 0.3$ & $2.1 \pm 0.4$ & 9 & \\
\hline \multirow[t]{2}{*}{ 21. lev $-10(\times 17)$} & - & $1.2 \pm 0.1$ & $4.3 \pm 0.6$ & $1.0 \pm 0.2$ & 10 & 2.53 \\
\hline & + & $2.1 \pm 0.1$ & $2.1 \pm 0.2$ & $1.0 \pm 0.3$ & 10 & \\
\hline \multicolumn{7}{|c|}{ Partially resistant mutants with spasmodic muscle twitching } \\
\hline \multirow[t]{2}{*}{ 22. lev-11(×12) } & - & $2.6 \pm 0.2$ & $3.3 \pm 0.5$ & $1.9 \pm 0.7$ & 10 & 1.30 \\
\hline & + & $3.8+0.4$ & $2.1+0.5$ & $3.8+1.1$ & 10 & \\
\hline \multirow[t]{2}{*}{ 23. $u n c-22(e 66)$} & - & $2.0 \pm 0.2$ & $8.5 \pm 1.1$ & $2.2 \pm 0.3$ & 9 & 2.23 \\
\hline & + & $3.7 \pm 0.4$ & $2.6 \pm 0.5$ & $2.5 \pm 0.9$ & 10 & \\
\hline \multicolumn{7}{|c|}{ Uncoordinated mutant with no levamisole resistance } \\
\hline \multirow[t]{2}{*}{ 24. unc- $68(\times 14)$} & - & $1.3 \pm 0.1$ & $6.3 \pm 0.6$ & $1.7 \pm 0.1$ & 9 & 2.48 \\
\hline & + & $2.7 \pm 0.2$ & $2.3 \pm 0.3$ & $2.5 \pm 0.5$ & 11 & \\
\hline
\end{tabular}

The saturable and nonsaturable specific ${ }^{3} \mathrm{H}-\mathrm{MAL}$ binding activities present in wild-type and 23 mutant extracts are shown. Each well-fed worm extract was assayed in the absence $(-)$ and presence $(+)$ of 1 mM mecamylamine (Mec.), and the predicted saturable and nonsaturable activities are shown both with and without $1 \mathrm{~mm}$ mecamylamine. Metaaminolevamisole $(10 \mu \mathrm{M})$ was the unlabeled competitor. The parameters for the saturable activity in an extract are given by the total amount of saturable activity and the dissociation constant, and, for the nonsaturable activity, by the slope of a line (see Materials and Methods). For each extract, measurements of specific ${ }^{3} \mathrm{H}-\mathrm{MAL}$ binding were normalized to AChE activity to correct for any differences in ${ }^{3} \mathrm{H}-\mathrm{MAL}$ binding between extracts that might be caused by age differences in the mixed-age populations of worms used to make the extracts. The actual activity measured may be calculated hy multiplying the appropriate parameters by the AChE activity given for each extract. $1 \mathrm{fmol}=24.8 \mathrm{cpm}$. The number of mean specific ${ }^{3} \mathrm{H}-\mathrm{MAL}$ determinations done for each extract between 0.17 (or 0.87 ) and 104 nM is shown. Some mutants (nos. 2-7) have low total saturable binding, and consequently the dissociation constants for these mutants are poorly defined (ND, not determinable).

a For 3 of these data sets, it was difficult to decide whether low total binding or a weak dissociation constant better explained the data, and the low amount of overall binding is represented by a single parameter for low-affinity nonsaturable binding. 
Figure 1. Specific ${ }^{3} \mathrm{H}-\mathrm{MAL}$ binding in an extract of well-fed wild-type nematodes, assayed with and without mecamylamine. Binding activity was measured and analyzed as described in Materials and Methods. Ligand binding is shown in femtomoles of specific ${ }^{3} \mathrm{H}-\mathrm{MAL}$ bound/mg total extract protein normalized per unit AChE. Meta-aminolevamisole (MAL; $10 \mu \mathrm{M})$ was the unlabeled competitor. $1 \mathrm{fmol}=24.8 \mathrm{cpm}$. Binding parameters and AChE activity are summarized in Table 2, no. 1. Specific ${ }^{3} \mathrm{H}-\mathrm{MAL}$ bound per unit AChE vs ${ }^{3} \mathrm{H}-\mathrm{MAL}$ concentration is shown in the inset; the main section shows the data as a Scatchard plot. Fitted curves were derived from SAS NLIN analysis of the data. Nonspecific binding increased linearly with increasing ${ }^{3} \mathrm{H}$ MAL concentration and was 3-4 $\mathrm{fmol} / \mathrm{mg}$ protein/unit AChE at 104 nM, the highest ${ }^{3} \mathrm{H}-\mathrm{MAL}$ concentration assayed. Specific ${ }^{3} \mathrm{H}-\mathrm{MAL}$ bound in the presence of $1 \mathrm{~mm}$ mecamylamine, $\longrightarrow$; specific ${ }^{3} \mathrm{H}-\mathrm{MAL}$ bound in the absence of $1 \mathrm{~mm}$ mecamylamine, $\square-\square$.

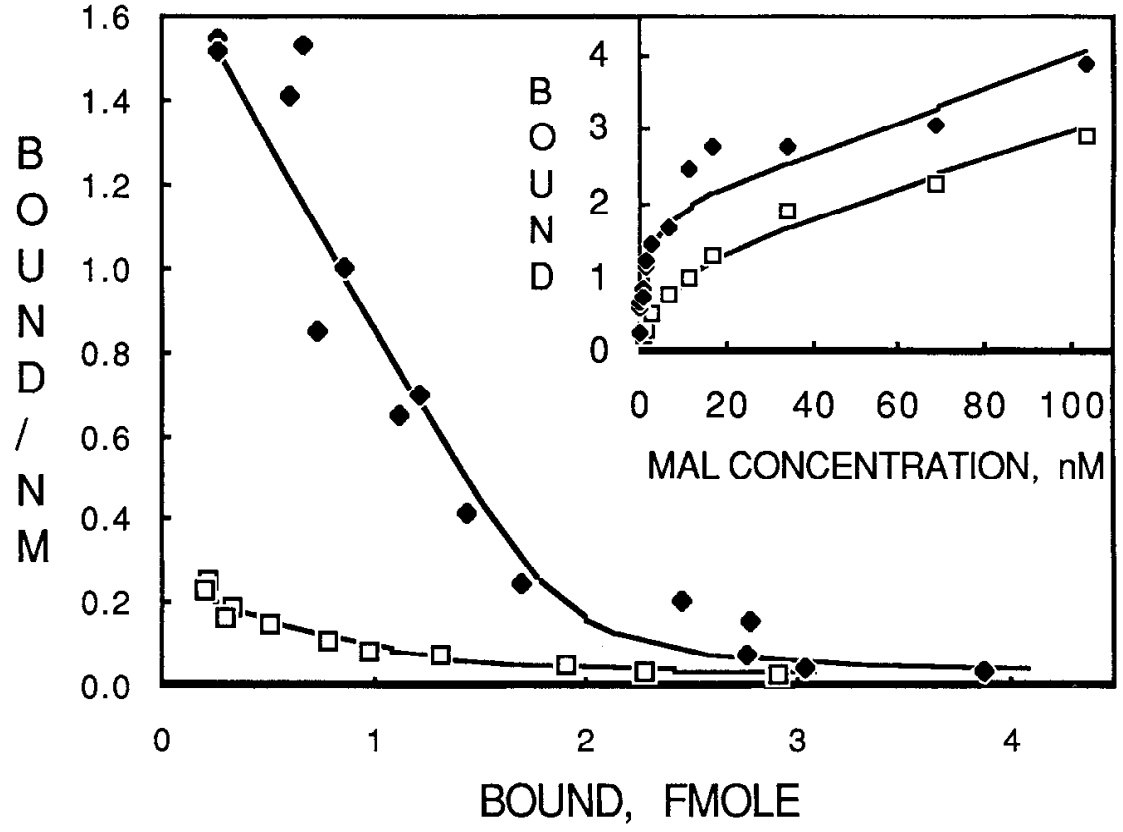

nations of specific ${ }^{3} \mathrm{H}-\mathrm{MAL}$ binding (pooled variance for total and nonspecific assays). Error increased as a linear function of the ${ }^{3} \mathrm{H}-\mathrm{MAL}$ concentration used in the assay, but we felt that weights derived purely from the variance associated with individual mean data points provided a greater safeguard against possibly wild individual determinations of mean specific binding. In the analysis of each extract, one determination of mean specific ${ }^{3} \mathrm{H}$-MAL binding at the lowest ${ }^{3} \mathrm{H}$-MAL concentrations assayed was chosen on the basis of its typical variance to carry a base weight of 1.0. Other points whose variances were less were forced to carry a weight of 1.0 also. All points with greater variance were assigned a lesser weight in inverse proportion to the variance of the point carrying the base weight of 1.0. The choice of weights on the basis of individual variances may not provide the minimum possible estimates of error in fitting parameters, but the parameter estimates themselves will still be unbiased (Draper and Smith, 1981). Fitted data points were examined for the size of associated Studentized residuals, weighted leverage, and the very approximate parameter $\left(t_{i}^{2} /(p+1) \times\left(h_{i i} /\left(1-h_{i l}\right)\right.\right.$ borrowed from linear regression (Gunst and Mason, 1980) and crudely indicative of the influence that the $i$ th point has on the parameter estimates $\left(t_{i}\right.$ and $h_{i i}$ are the Studentized residual and the weighted leverage for the $i$ th point, $p$ the number of model parameters). Data points having exceptionally large values for any of these statistical parameters were either deleted or assigned a reduced weight.

In both untransformed and Scatchard plots of the data, the total ligand concentration added to the assay was used as the free ligand concentration, unless the calculated free ligand concentration dropped below $97 \%$ of the total ligand concentration.

For the wild type and most mutants, more than one binding component was observed. Only the highest-affinity component was saturable within the range of the binding assay and therefore readily characterized in terms of total binding $\left(B_{\max }\right)$ and a ligand equilibrium dissociation constant $\left(K_{\mathrm{d}}\right)$. Thus, for the most part, we used a binding model of a hyperbola and line to fit the high- and low-affinity components, respectively, subsuming all low-affinity components present into a singleslope parameter for a linearly increasing, nonsaturable component. The addition of mecamylamine increased the ligand binding affinity of both high- and low-affinity components, making the low-affinity component, at least for the wild type, more saturable. In mixed-age populations of well-fed worms, the most complex binding model allowed by the total amount of binding was still a 3-parameter hyperbola and line model. Such a model provides a reasonable characterization of the ligand affinity of the high-affinity component in the presence of mecamylamine, but errs in including some of the low-affinity component in the estimate of total high-affinity binding (compare the wild type assayed with and without mecamylamine in Table 2, no. 1). Even with allowance for this limitation, some striking differences in total high-affinity binding or mecamylamine response are seen between the wild type and some mutants using well-fed worm extracts. In starved wild-type worm extracts, there was 4-6 times as much binding activity, and a 2-hyperbola model could be used to characterize both high- and low-affinity wild-type binding components in the presence of mecamylamine. The binding activities present in starved worm extracts of most mutants were still well fitted by a hyperbola and line model whether or not mecamylamine was present.

\section{Results}

Two different assay conditions show mutants are different from the wild type

Binding assays conducted under 2 different sets of conditions show that mutants of the 7 genes associated with extreme levamisole resistance have deficient or altered levamisole binding activity. Under one set of conditions, we assayed mixed-age populations of well-fed worms. Since adult hermaphrodites of $C$. elegans lay eggs continuously, large quantities of well-fed animals of uniform age cannot readily be generated. Receptor binding per milligram extract protein is highest in the early larval stages and decreases severalfold in adult animals, perhaps because of the relative growth of non-neuromuscular tissue like the gut and the gonad in the adult animal (Lewis et al., 1987). Using mixed-age populations of well-fed wild-type worms, we could maximally assay about $130 \mathrm{cpm}$ of specific ${ }^{3} \mathrm{H}-\mathrm{MAL}(5$ $\mathrm{fmol} / \mathrm{mg}$ extract protein at the highest practicable ligand concentrations in our assay (Fig. 1). Possible variations in age structure between populations have been taken into account by normalizing to cholinesterase-specific activity, as in Figure 1. Wild-type ${ }^{3} \mathrm{H}-\mathrm{MAL}$ binding, as shown also in Figure 1 , is allosterically activated by $1 \mathrm{~mm}$ mecamylamine, a noncompetitive cholinergic antagonist. Upon screening all our mutants, using $10 \mu \mathrm{M}$ unlabeled MAL as a competitor in the determination of nonspecific binding, the most deficient type of mutant we could find still retained a low-affinity component whose 


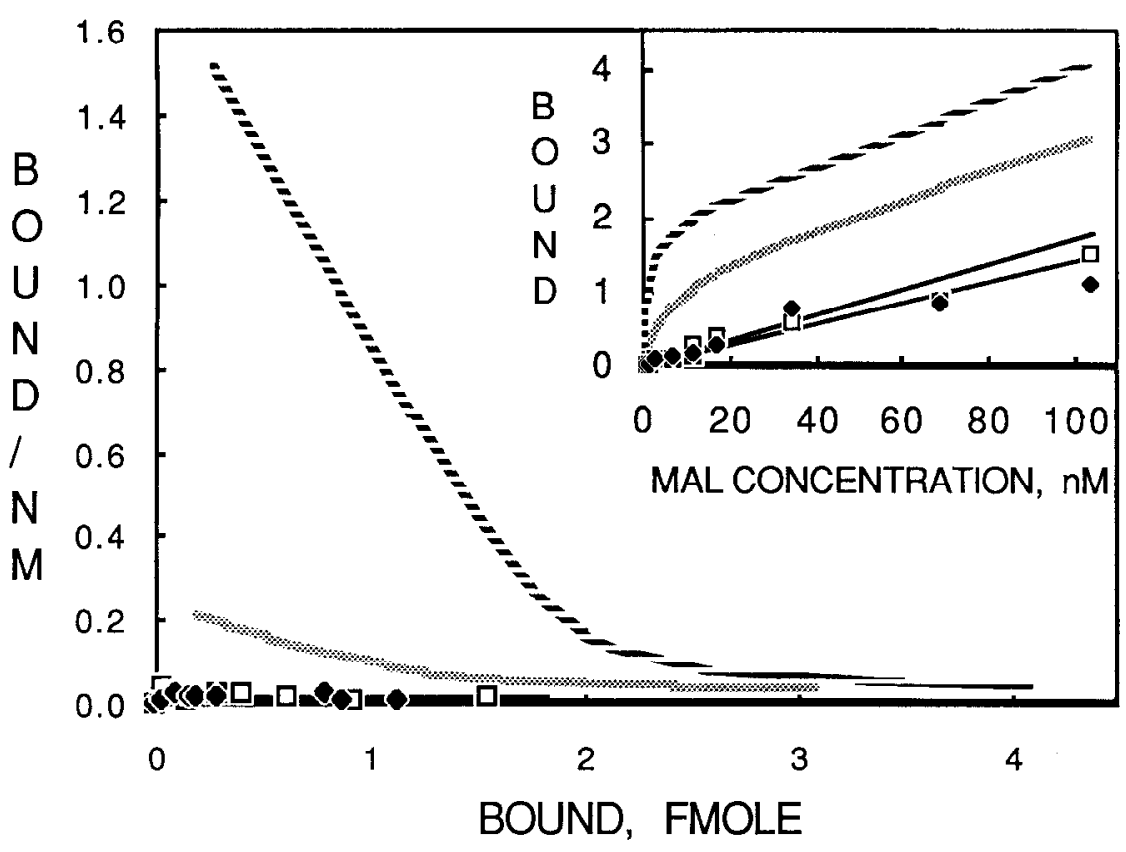

Figure 2. Specific ${ }^{3} \mathrm{H}-\mathrm{MAL}$ binding in an extract of well-fed unc- $74(\times 55)$, a mutant deficient in saturable highaffinity binding activity (Table 2 , no. 7). Binding was assayed with and without mecamylamine and the data plotted as for Figure 1. Unc-74( $\times 55)$ with $1 \mathrm{~mm}$ mecamylamine, with no mecamylamine, $\square-\square$. In addition, the predicted wild-type binding curves taken from Figure 1 are shown for reference. Wild type with mecamylamine (heavy broken line); wild type without mecamylamine (light stippled line). binding properties were not altered by the addition of mecamylamine (Fig. 2). Such mutants were highly deficient in detergent-soluble ${ }^{3} \mathrm{H}-\mathrm{MAL}$ binding, but had wild-type amounts of detergent-insoluble ${ }^{3} \mathrm{H}-\mathrm{MAL}$ binding. It seemed likely that the low-affinity binding remaining in the most deficient mutants might correspond to the detergent-insoluble component and be unrelated to the true, physiologically active, levamisole receptor, which appears to be detergent-soluble.

We subsequently found a more advantageous set of assay conditions, at least for assaying wild-type activity. In worm populations starved for 1 week, adults die off, and dauer larvae, a special juvenile stage designed to survive conditions of starvation and overcrowding, accumulate among the predominantly younger-stage juveniles that survive starvation. Wild-type starved worms have 4-6-fold increased specific ${ }^{3} \mathrm{H}-\mathrm{MAL}$ binding $/ \mathrm{mg}$ extract protein, representing about $600-700 \mathrm{cpm}$ of total binding at saturation (Table 3, no. 1; Fig. 3). The increase in receptor activity is probably attributable to the higher proportion of young juveniles, and possibly to the preferential survival of receptor protein in starved populations. In comparing assayable activities in starved wild type and the most receptor-deficient mutants, 0.5 mm dimethylphenylpiperazinium was found to be a more selective competitor, eliminating the backgroundspecific ${ }^{3} \mathrm{H}-\mathrm{MAL}$ binding component observed in highly receptor-deficient mutants when $10 \mu \mathrm{M}$ unlabeled MAL was used as the competitor (Fig. 4). A disadvantage of using starved worm extracts is that some mutant receptors appear to be degraded as compared to the receptor activity observable in the same strains assayed as well-fed worms. The wild-type receptor, as judged by its high-affinity component, suffers at worst a 2-fold decrease in ${ }^{3} \mathrm{H}-\mathrm{MAL}$ affinity (Table 3 , no. 1 vs Table 2 , no. 1). The overriding conclusion under either set of assay conditions, however, is that clear-cut differences exist, as discussed below, between wild-type and mutant receptors.

\section{Abnormalities of receptor binding in mutants of extreme levamisole resistance loci}

The receptor abnormalities seen in mutants of the 7 genes associated with extreme levamisole resistance fall into 3 different categories: (1) mutants of 3 genes, unc-29, unc-50, and unc-74, are severely deficient in saturable binding activity; (2) mutants of 3 other genes, $u n c-38$, unc-63, and lev-7, show saturable binding activity that, at least in part, represents activity in an abnormally high-affinity state; the addition of the allosteric aclivating agent mecamylamine causes no further increase in receptor affinity; (3) mutants of the lev-1 gene show remarkable variations in receptor activity, depending on which particular $l e v-1$ mutant is assayed. Extremely levamisole-resistant lev-1 mutants, probably originating from an altered but functional lev- 1 gene product, have normal amounts of saturable binding that, at least for the $l e v-l(\times 61)$ mutant, shows increased ligand affinity even without the addition of the activating agent, mecamylamine. Much more common, but only partially levamisoleresistant $l e v-1$ mutants, that paradoxically probably result from elimination of the $l e v-1$ gene product, usually have a receptor in a constitutively low-affinity state not activatable by mecamylamine.

\section{Receptor deficiency in unc-29, unc-50, and unc-74 mutants}

We assayed well-fed worm extracts from 2 mutants each of the unc-29, unc-50, and unc-74 genes in the presence and absence of the activating agent mecamylamine. All the mutants were deficient in saturable high-affinity specific ${ }^{3} \mathrm{H}-\mathrm{MAL}$ binding (Table 2, nos. 2-7), and the addition of mecamylamine had no effect. A residual low-affinity binding activity remains in these mutants using $10 \mu \mathrm{M}$ unlabeled MAL as a competitor in the determination of nonspecific binding, as explained above. Even so, all these mutants have an average of $10 \pm 3 \%$ of the activity found in the wild type when assayed at $17 \mathrm{nM}{ }^{3} \mathrm{H}-\mathrm{MAL}$ with $1 \mathrm{~mm}$ mecamylamine present, and are thus clearly receptordeficient compared to the wild type.

To more clearly demonstrate the lack of specific ${ }^{3} \mathrm{H}-\mathrm{MAL}$ binding, we reassayed one mutant each of the unc-29, unc-50, and unc-74 genes, using starved worm extracts and $0.5 \mathrm{~mm}$ dimethylphenylpiperazinium as the unlabeled competitor. The data, obtained with $1 \mathrm{~mm}$ mecamylamine present (Fig. 4; Table 3 , nos. 2-4), show that there is littlc or no saturablc binding activity in these mutants, and that the use of dimethylphenyl- 
Figure 3. Specific ${ }^{3} \mathrm{H}-\mathrm{MAL}$ binding in an extract of starved wild-type nematodes (Table 3, no. 1). The data are presented as described for Figure 1 , except that specific ${ }^{3} \mathrm{H}-\mathrm{MAL}$ bound is given as $\mathrm{fmol} / \mathrm{mg}$ total extract protein and is not normalized to AChE activity. Dimethylphenylpiperazinium $(0.5 \mathrm{mM})$ was the unlabeled competitor. The amount of nonspecific ${ }^{3} \mathrm{H}-$ MAL binding linearly increased with increasing ${ }^{3} \mathrm{H}-\mathrm{MAL}$ concentration and was about $30 \mathrm{fmol}$ at $100 \mathrm{~nm}{ }^{3} \mathrm{H}$ MAL. With $1 \mathrm{~mm}$ mecamylamine, ; with no mecamylamine,

piperazinium eliminates the background binding activity that was observed in well-fed worm extracts of these mutants (Fig. 4). The unc-29( $\times 29)$ mutant assayed does seem to have a small amount of residual saturable activity (Fig. 5). The lack of coordination of this mutant is modest compared to that of other extremely levamisole-resistant unc-29 mutants. The unc$29(\times 29)$ mutant might be a mutant for which the total amount, rather than the functionality, of the levamisole receptor has been lowered by mutation.

\section{Mutants of unc-38, unc-63, and lev-7 with abnormally high-affinity activity}

We tested 2 mutants each of the $u n c-38$ and $u n c-63$ genes, and the one known mutant of $l e v-7$, using well-fed worm extracts (Tablc 2, nos. 8-12). The saturable high-affinity binding activity in these mutants had an unusually high affinity for ${ }^{3} \mathrm{H}-\mathrm{MAL}$ in the absence of mecamylamine. Binding could not be further activated by mecamylamine [see $u n c-63(\times 37)$, Fig. 6]. The affinity that all these mutants show, with or without mecamylamine, is about the same as that of the wild-type receptor with mecamylamine present.

To corroborate these results, we reassayed one mutant of each of the $u n c-38, u n c-63$, and lev-7 genes, using starved worm extracts (Table 3, nos. 5-7; Fig. 7). For each of these 3 mutants grown as starved worms, there is a greatly reduced amount of the high-affinity binding site as compared to that in the wild type (Table 3, no. 1). With no mecamylamine added, the ligand binding affinity of the high-affinity site in the mutants approaches that of the wild-type site activated by mecamylamine. For the $u n c-38$ and $l e v-7$ mutants, there is also a considerable
Figure 4. Specific ${ }^{3} \mathrm{H}-\mathrm{MAL}$ binding in an extract of starved $u n c-50(e 306)$, a mutant with no saturable or nonsaturable activity, assayed in the presence of $1 \mathrm{~mm}$ mecamylamine (Table 3 , no. 3). Binding is plotted as for Figure 3 . The predicted curve is shown as a stippled line for clarity.

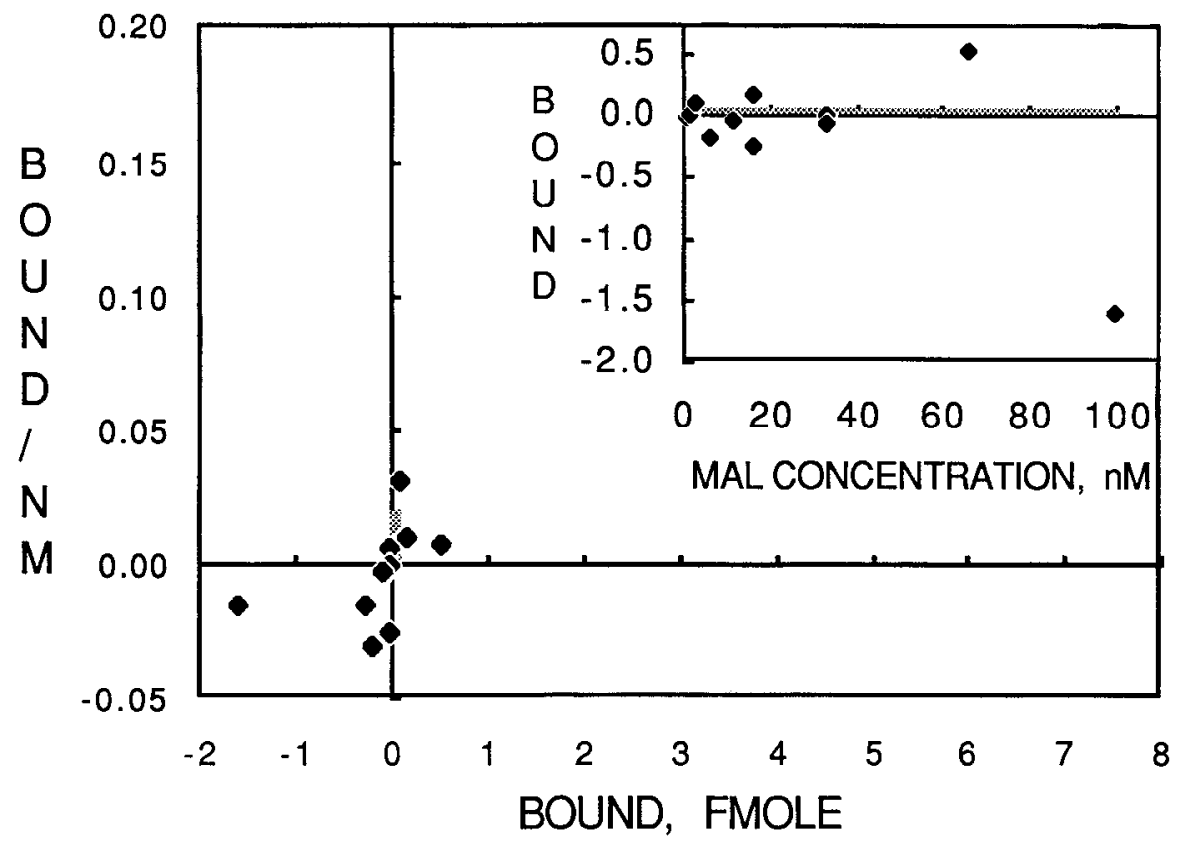


Table 3. Binding activity in the wild type and levamisole-resistant mutants grown as starved worms

\begin{tabular}{|c|c|c|c|c|c|c|c|}
\hline Strain & Mec. & $\begin{array}{l}B_{\max 1} \\
\text { (fmol } / \mathrm{mg})\end{array}$ & $\begin{array}{l}K_{\mathrm{d} 1} \\
(\mathrm{nM})\end{array}$ & $\begin{array}{l}B_{\max 2} \\
(\mathrm{fmol} / \mathrm{mg})\end{array}$ & $\begin{array}{l}\text { or } \\
\text { nonsatu- } \\
\text { rable } \\
(\mathrm{fmol} / \mathrm{mg} / \\
\mathrm{nM} \times \\
\left.10^{-2}\right) \\
\end{array}$ & $\begin{array}{l}K_{\mathrm{d} 2} \\
(\mathrm{nM})\end{array}$ & $\begin{array}{l}\text { No, } \\
\text { of } \\
\text { data } \\
\text { points }\end{array}$ \\
\hline \multirow[t]{3}{*}{ 1. $\mathrm{N} 2$, wild type } & - & $13.3 \pm 0.6$ & $9.4 \pm 0.6$ & & $5.8 \pm 0.8$ & & 14 \\
\hline & or & $13.3 \pm 0.6$ & $9.4 \pm 0.6$ & 13.5 & & 167 & \\
\hline & + & $13.5 \pm 0.7$ & $1.3 \pm 0.1$ & $13.2 \pm 0.9$ & & $31.6 \pm 8.7$ & 14 \\
\hline
\end{tabular}

Mutants with little or no saturable activity

$\begin{array}{llll}\text { 2. } u n c-74(\times 19) & + & 0 \pm 0.4 & \mathrm{ND} \\ \text { 3. } u n c-50(e 306) & + & 0.01 \pm 0.04 & \mathrm{ND} \\ \text { 4. } u n c-29(\times 29) & + & 0.2 \pm 0.1 & 1.9 \pm 2.1\end{array}$

Mutants with altered ligand binding activity
5. unc $-38(\times 20)$
$\begin{array}{lll}- & 2.2 \pm 0.2 & 3.0 \pm 0.6\end{array}$
$+\quad 2.0 \pm 0.1 \quad 3.2 \pm 0.3$
6. $u n c-63(\times 37)$
$-$
$2.5 \pm 0.1$
$1.4 \pm 0.1$
7. $\operatorname{lev}-7(\times 13)$
$+$
$2.6 \pm 0.1$
$1.7 \pm 0.2$
$+$
$2.3 \pm 0.1$
$2.9 \pm 0.2$
$1.6 \pm 0.1 \quad 1.7 \pm 0.4$

Mutants associated with the lev- 1 locus
8. lev- $1(\times 61)$
$+$
$10.1 \pm 3.3$
$1.7 \pm 0.5$
$11.7 \pm 2.4$
$12.2 \pm 0.6$
9. $l e v-1(\times 22)$
$7.7 \pm 0.7$
$0.6 \pm 0.1$
$-\quad 4.2 \pm 0.4 \quad 4.9 \pm 0.8$
$+\quad 3.3 \pm 0.5 \quad 4.3 \pm 1.1$
$14 \pm 9 \quad 17$
$10 \pm 2 \quad 11$
$4.6 \pm 0.7 \quad 11$
$1.7 \pm 0.8 \quad 11$

$0 \pm 0.7$

$0 \pm 0.4$

$0 \pm 0.5$

19

11

11

$\begin{array}{ll}3.2 \pm 0.4 & 22 \\ 2.3 \pm 0.3 & 11 \\ 0.6 \pm 0.4 & 12 \\ 0.3 \pm 0.3 & 11 \\ 4.3 \pm 0.2 & 19 \\ 2.9 \pm 0.3 & 11\end{array}$

The specific ${ }^{3} \mathrm{H}-\mathrm{MAL}$ binding activities present in the wild-type and 8 levamisole-resistant mutants grown as starved worms were determined in the absence $(-)$ or the presence $(+)$ of 1 mM mecamylamine (Mec.). Dimethylphenylpiperazinium $(0.5 \mathrm{~mm})$ was the unlabeled competitor. $1 \mathrm{fmol}=24.8 \mathrm{cpm}$. Binding activity was fitted either to a model of a highaffinity saturable activity and a low-affinity nonsaturable activity, and 3 parameters given, or fitted to a model of highand low-affinity saturable activities, with 4 parameters given. $B_{\max }=$ total binding, $K_{\mathrm{d}}=$ dissociation constant for saturable activity. For the wild type assayed without mecamylamine, an estimate of the $B_{\max }$ and $K_{\mathrm{d}}$ of a low-affinity saturable activity was obtained by constraining a 2-hyperbola model to the values of $B_{\max }$ and $K_{\mathrm{d} 1}$ estimated from a hyperbola and line model. Unlike Table 2, binding parameters are not normalized to AChE activity. The AChE activities for each strain were $4.58,2.50,1.84,4.92,3.92,3.42,4.56,4.48$, and 4.55 , respectively. $\mathrm{ND}$, not determinable.

amount of nonsaturable, low-affinity binding activity present, even in the presence of $1 \mathrm{~mm}$ mecamylamine, an agent that makes the lower-affinity activity of the wild type saturable. On the contrary, the $u n c-63(\times 37)$ mutant has strikingly little ac- tivity that is not attributable to its high-affinity site (Fig. 8). The addition of mecamylamine causes no change in binding, as found for the assay of well-fed worm extracts of these mutants, except for the possible modest inhibition of some activity $[$ lev- $7(\times 13)$;

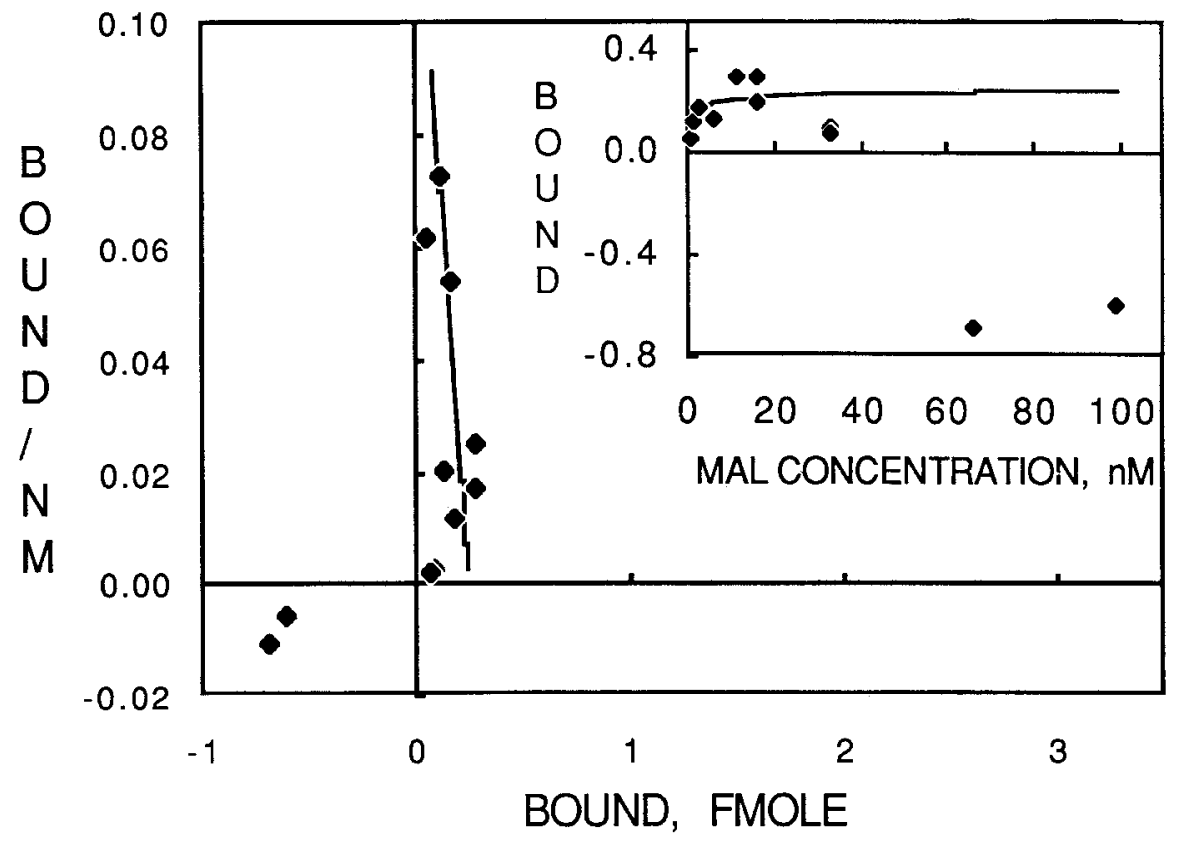

Figure 5. Specific ${ }^{3} \mathrm{H}-\mathrm{MAL}$ binding in an extract of starved unc-29( $\times 29)$, a mutant with a very small amount of binding activity, assayed in the presence of $1 \mathrm{~mm}$ mecamylamine (Table 3, no. 4). Binding plotted as for Figure 3. 

in an extract of well-fed $u n c-63(\times 37)$, a mutant with saturable high-affinity binding activity unaffected by mecamylarnine (Table 2, no. 11). Binding plotted as for Figure 2 . unc- $63(\times 37)$ with $1 \mathrm{~mm}$ mecamylamine, with no mecamylamine, $\square-\square$. Predicted wild-type curves: with mecamylamine (heavy broken line); without mecamylamine (light stippled line).
Figure 6. Specific ${ }^{3} \mathrm{H}-\mathrm{MAL}$ binding

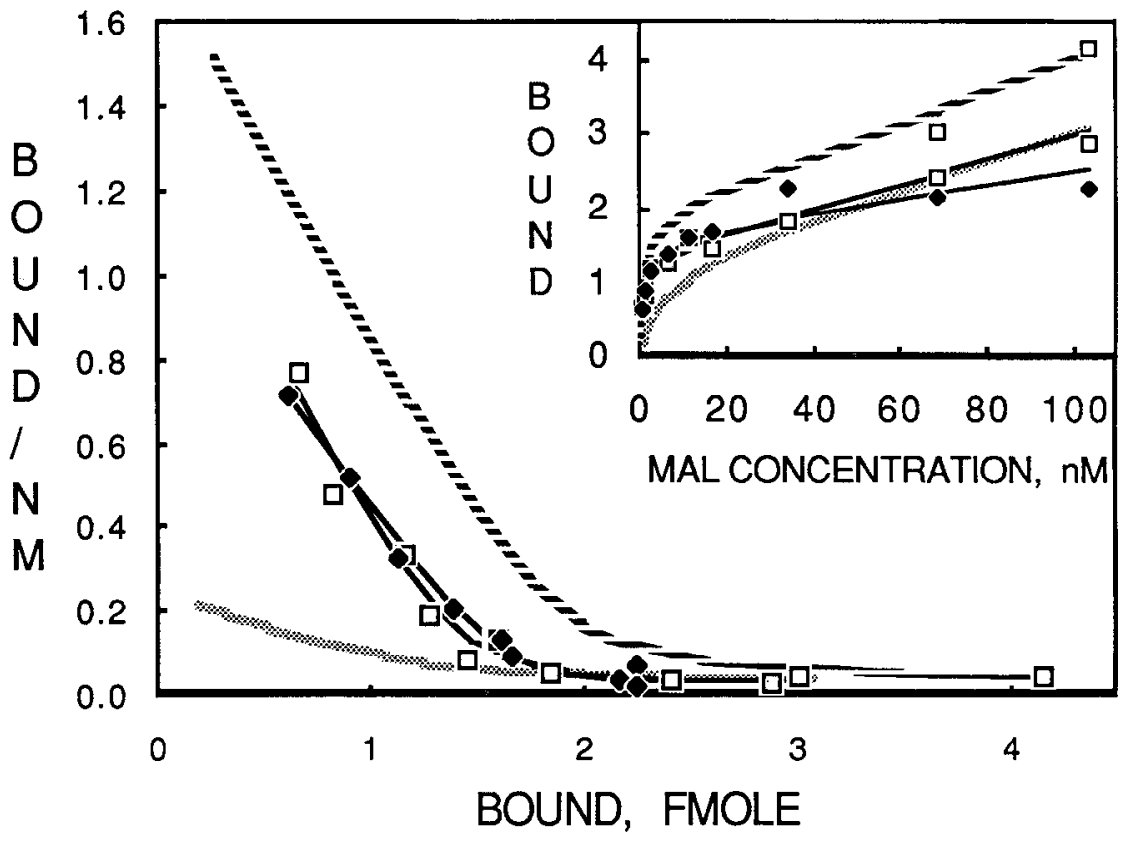

Table 3, no. 7]. Since the use of $0.5 \mathrm{~mm}$ dimethylphenylpiperazinium eliminates nonlevamisole receptor ${ }^{3} \mathrm{H}-\mathrm{MAL}$ background binding, as demonstrated by the unc-29, unc-50, and unc-74 mutants, the low-affinity, nonactivatable ${ }^{3} \mathrm{H}-\mathrm{MAL}$ binding components seen in the $u n c-38$ and $l e v-7$ mutants must arise by mutation of the levamisole receptor sites found in the wild type.

\section{Mutants of the lev-1 gene}

We have tested both extremely and partially levamisole-resistant mutants of the $l e v-I$ gene. Partially resistant mutants of the $l e v-1$ gene are very easy to isolate (Brenner, 1974; Lewis et al., $1980 \mathrm{a}$ ), while extremely resistant mutants are exceedingly rare ( 2 of 211 extremely resistant mutants; Lewis et al., 1980a). The levamisole resistance of the partially resistant mutants is reces- sive to the drug sensitivity of the wild type, while that of the rare, extremely resistant lev- 1 mutants is semidominant. The rarity and semidominant nature of the extremely resistant $l e v-1$ alleles lead us to believe that the extremely resistant alleles produce a specifically altered gene product that has a more deleterious effect on levamisole receptor function than does the simple elimination of the $l e v-1$ gene product, which we believe results in the more common, partially resistant $l e v-1$ alleles. A corollary of this hypothesis is that lev-1, since it appears genetically dispensable, is not essential for the developmental expression or function of the receptor, but has some peripheral modifying role in receptor function. Our binding results are consistent with these ideas.

Both extremely resistant lev-1 mutants that we assayed as well-fed worm cxtracts have closer to normal receptor binding
Figure 7. Specific ${ }^{3} \mathrm{H}-\mathrm{MAL}$ binding in an extract of starved $u n c-38(\times 20)$, a mutant with reduced levels of highaffinity activity and substantial receptor-related nonsaturable activity, neither potentiable by mecamylamine (Table 3, no. 5). Binding plotted as for Figure 3. Unc-38 $(\times 20)$ with $1 \mathrm{~mm}$ mecamylamine, $\longrightarrow$; with no mecamylamine,

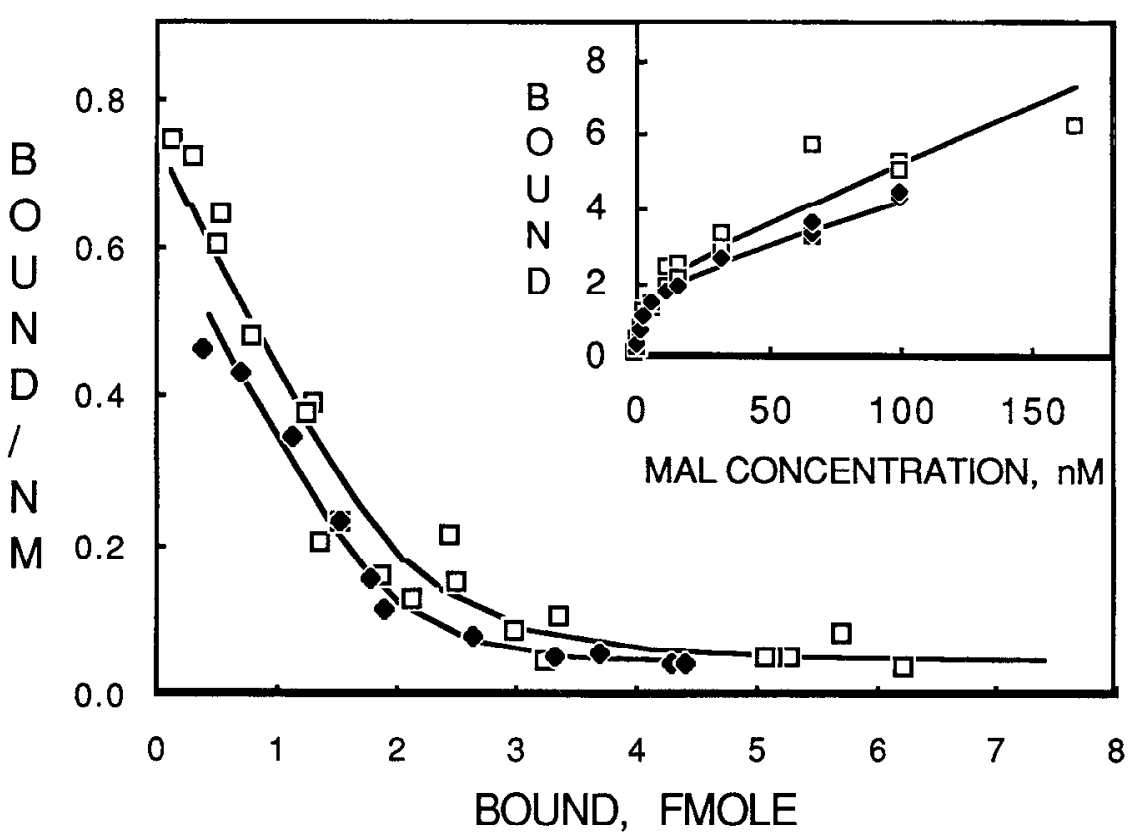




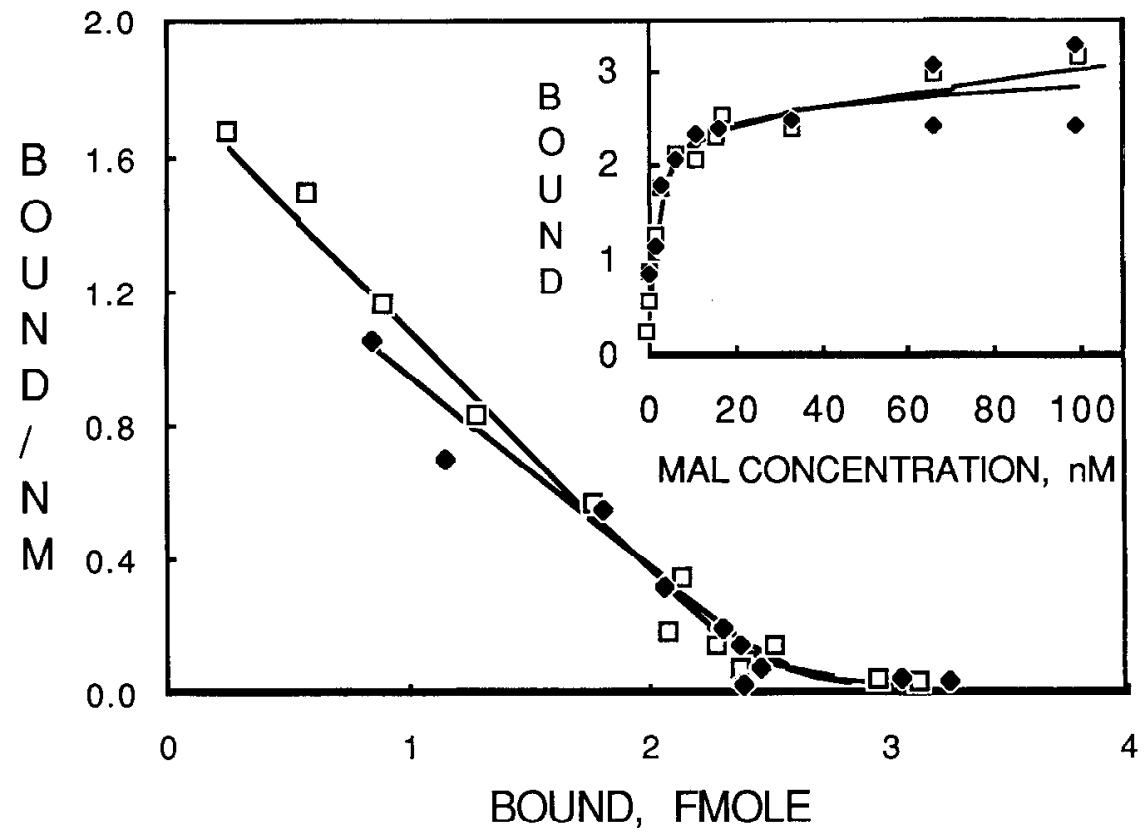

Figure 8. Specific ${ }^{3} \mathrm{H}-\mathrm{MAL}$ binding in an extract of starved unc- $63(\times 37)$, a mutant with reduced levels of highaffinity activity and little receptor-related nonsaturable activity, neither potentiable by mecamylamine (Table 3 , no. 6). Binding plotted as for Figure 3. unc-63(×37) with $1 \mathrm{~mm}$ mecamylamine, amine, $\square-\square$. activity than any other of the extremely resistant mutants assayed [lev-1 $(\times 61)$ and $l e v-1(\times 21)$; Table 2 , nos. 13 and 14$]$. In fact, over the range of ligand concentrations assayed, these mutants appear to have $50-100 \%$ more high-affinity specific ${ }^{3} \mathrm{H}$ MAL binding activity than is found in the wild type assayed without mecamylamine. The apparent increase in ligand binding affinity caused by mecamylamine also does not appear to be as great as for the wild type.

These observations are explained, at least in part, by the reassay of the mutant lev- $1(\times 61)$ using a starved worm extract (Table 3, no. 8; Fig. 9). As for the wild type, both high- and low-aftinity ${ }^{3} \mathrm{H}-\mathrm{MAL}$ binding receptor sites are readily detectable. Both sites seem to be endogenously in a higher affinity state, and the addition of mecamylamine to the assay causes little further increase in affinity. The apparent increase in total high-affinity binding sites observed in well-fed worm extracts of the lev-1 $(\times 61)$ mutant could thus result from the inclusion of some of the endogenously activated lower-affinity sites in the estimate of the total high-affinity ligand binding sites when using the simpler hyperbola and line binding model necessitated by the lower amount of activity in well-fed worm extracts.

The 2 partially resistant $l e v-1$ mutants that we assayed as wellfed worm extracts have much more abnormal saturable ${ }^{3} \mathrm{H}$ MAL binding activity $[l e v-l(\times 22)$ and $l e v-l(\times 38)$; Table 2 , nos. 15 and 16$]$. Both mutants show very little response to mecamylamine: $l e v-1(\times 22)$ remains in the low-affinity ground state of

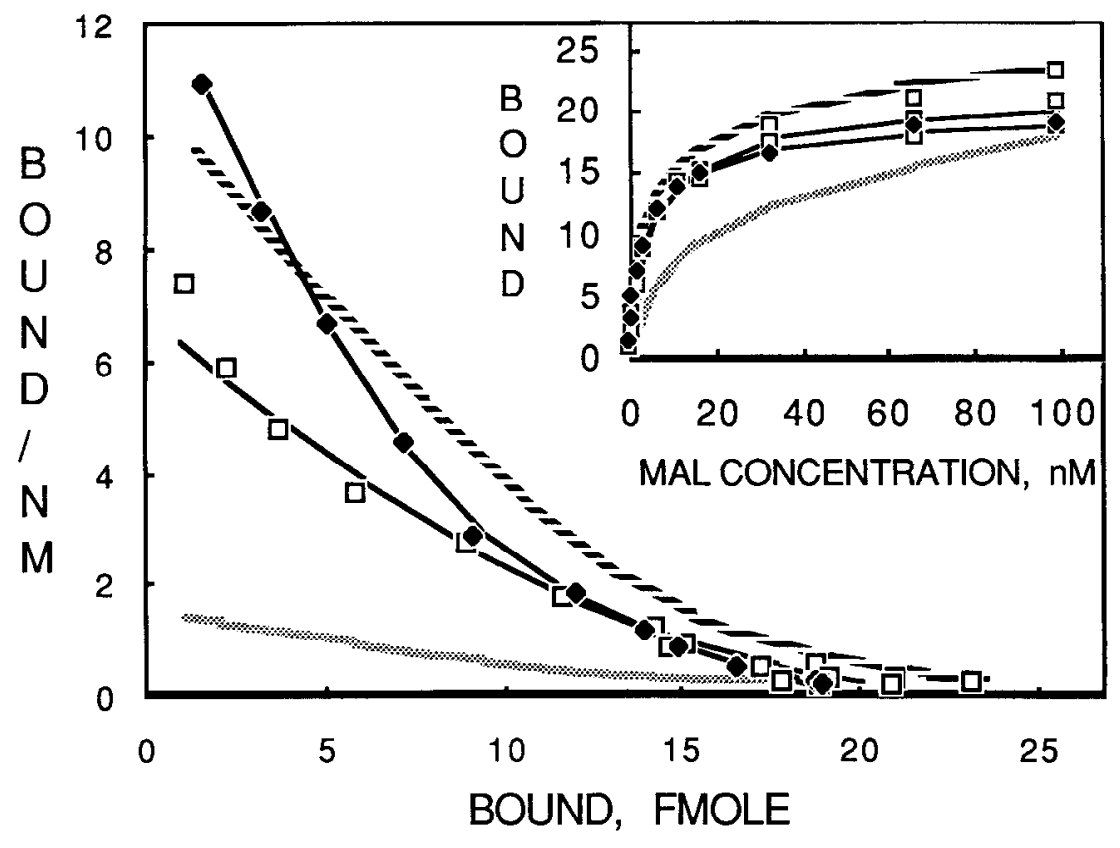

Figure 9. Specific ${ }^{3} \mathrm{H}-\mathrm{MAL}$ binding in an extract of starved lev-1 $(\times 61)$, a mutant with increased ligand affinity and normal amounts of total binding (Table 3 , no. 8 ). Binding plotted as for Figure 3. lev-1 $(\times 61)$ with $1 \mathrm{~mm}$ mecamylamine, $\longrightarrow$; with no mecamylamine, $\square-\square$. Predicted wild-type curves: with mecamylamine (heavy broken line); without mecamylamine (light stippled line). 
Figure 10. Specific ${ }^{3} \mathrm{H}-\mathrm{MAI}$ binding in an extract of well-fed $l e v-l(\times 22)$, a mutant with binding activity trapped in a low-affinity state not activatable by mecamylamine (Table 2 , no. 15 ). Binding plotted as for Figure 2..lev$I(\times 22)$ with $1 \mathrm{~mm}$ mecamylamine, ; with no mecamylamine

the wild type without mecamylamine (Fig. 10) and lev- $1(\times 38)$ is always in the high-affinity state of the wild type with mecamylamine.

We reassayed the partially levamisole-resistant lev- $l(\times 22)$ mutant using a starved worm extract (Table 3 , no. 9). The data show reduced amounts of the high-affinity site and a significant amount of levamisole receptor-related nonsaturable activity. The inclusion of mecamylamine in the assay has no effect, except for the possiblc inhibition of somc of the nonsaturablc activity. The high-affinity binding site of this mutant has the lowest ligand binding affinity of all mutants that showed appreciable specific ${ }^{3} \mathrm{H}-\mathrm{MAL}$ binding when tested as starved worms, in agreement with the constitutively lower-affinity state found when a wellfed worm extract of this mutant was assayed.

Using well-fed worm extracts, we also assayed 2 spontaneous revertants of the $l e v-l(\times 6 l)$ and $l e v-l(\times 21)$ extreme resistance alleles. These revertants, ZZ1010 and ZZ1006, respectively, were found to have reverted to more wild-type motor behavior with simultaneous reversion to partial levamisole resistance. The reverting mutation in both instances is linked to the original $l e v-1$ mutation and "reversion" probably occurred by further mutation of the forms of $l e v-1$ found in $\times 61$ and $\times 21$. By ethyl methanesulfonate mutagenesis, we have also shown that $\times 61$ and $\times 21$ mutants can be reverted at a high rate consistent with nonspecific loss of a gene function. If the directly isolated, partially resistant $l e v-1$ mutants are really a more $l e v$ - $l$-deficient type of mutant than the extremely resistant kind, we might expect the revertants to have binding activity more like the partially resistant mutants described above. We find that they do. Our assay results are consistent with reversion by loss of lev- 1 function.

The receptor binding activity in both $l e v-1$ revertants is in a low-affinity state, unresponsive to mecamylamine (Fig. 11; Table 2 , nos. 17 and 18). The total amount of receptor, which had appeared elevated in the original $\times 61$ and $\times 21$ mutants, has fallen to wild-type levels (taking wild type without mecamylamine as a standard). For the $\times 61$ revertant, the apparent decrease in total binding might be expected if activation of the loweraffinity site found in the $\times 61$ mutant were undone by the second mutation in the revertant.
Partially resistant mutants of the lev- 8 , lev-9, and lev-10 genes

Partially levamisole-resistant mutants of $C$. elegans occur in a variety of genes besides the lev- 1 locus mentioned above. Partially resistant isolates, probably leaky alleles, have been identified for all the other extreme levamisole resistance genes described above, except for the $u n c-50$ and $l e v-7$ genes. In this work, wc clcctcd not to assay partially resistant mutants of $u n c-$ 29, unc-38, unc-63, and $u n c-74$, believing the uncoordinated mutants tested represent the most extreme phenotype for mutants of these genes.

Three other genes, $l e v-8$, lev-9, and $l e v-10$, are known to give rise to only partially levamisole-resistant mutants. These mutants show near wild-type motor behavior and a strong initial contractile response to levamisole, but, unlike the wild type, they recover and survive well in the presence of the drug (Lewis et al., 1980b). We tested the most resistant mutant known for each of these genes, and our results show that the receptor binding activity in these mutants is grossly normal.

The saturable binding activities in the lev- 8 , lev-9, and lev10 mutants all seem to respond to mecamylamine (Table 2, nos. 19-21). There appears to be 1.7 times more high-affinity saturable binding activity in the $l e v-8(\times 15)$ mutant. Because the high-affinity binding parameters are otherwise very similar to that of the wild type assayed with and without mecamylamine, it would be worthwhile to reassay this mutant using a starved worm extract to determine if the total binding has actually increased. There may also be moderate differences from wild type in the ${ }^{3} \mathrm{H}-\mathrm{MAL}$ binding affinities of the lev-9( $\left.\times 16\right)$ and lev$10(\times 17)$ mutants. Otherwise, the fairly normal binding behavior of these mutants is consistent with their responsiveness to levamisole.

\section{Twitcher mutants of unc-22 and lev-11}

Partially levamisole-resistant mutants are known for 2 other genes that are different from any described so far: unc-22 and lev- 11 produce levamisole-resistant mutants having an uncoordinated phenotype of spasmodic muscle twitching superimposed on normal sinusoidal motion (Brenner, 1974; Lewis et 


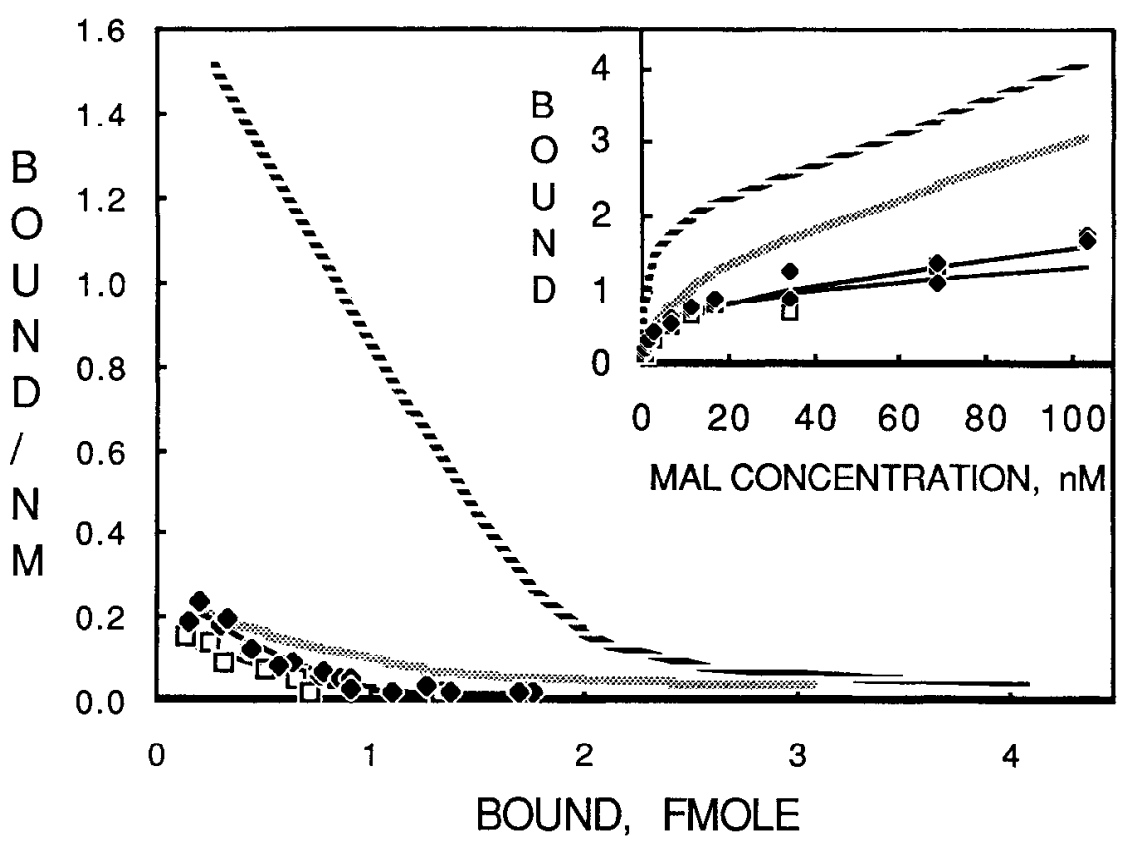

Figure 11. Specific ${ }^{3} \mathrm{H}-\mathrm{MAL}$ binding in an extract of well-fed ZZ1010, a revertant of $l e v-1(\times 61)$, with binding activity trapped in a low-affinity state not activatable by mecamylamine (Table 2, no. 18). Binding plotted as for Figure 2. ZZ1010 with 1 mM mecamylamine, no mecamylamine, $\square$ al., 1980a). These mutants, unlike other levamisole-resistant mutants, are also resistant to the noncholinergic muscle agonist ouabain (I ewis et al., 1980b). Defects in muscle structure itself have been observed in $u n c-22$ mutants (Waterston et al., 1980), and the protein encoded by the unc-22 gene has recently been localized histochemically to the A band of muscle ( $G$. Benian and D. Moerman, personal communication). The twitcher mutants thus appear to have defects at stages further along the pathway of muscle contraction than the initial site at which levamisole acts.

Our binding assays on well-fed worm extracts show that the amount of saturable ${ }^{3} \mathrm{H}-\mathrm{MAL}$ binding activity in both the mutants $u n c-22(e 66)$ and lev-11( $\times 12)$ is increased about 2-fold over the wild-type amount, whether one compares the derived binding parameters or the actual amount of specific ${ }^{3} \mathrm{H}-\mathrm{MAL}$ binding measured over the range of the assay (Table 2 , nos. 22 and 23; Fig. 12). The ligand binding affinity of both mutants is increased by mecamylamine, but less than for the wild type.

\section{Normal receptor activity in an unc-68 mutant}

unc- 68 mutants possess the same stereotyped uncoordinated motor behavior as do the extremely levamisole-resistant uncoordinated mutants described above, but they are sensitive to levamisole. The response to levamisole and ouabain is reduced in the head region, but otherwise $u n c-68$ mutants contract and die when exposed to levamisole (Lewis et al., 1980b). We think that $u n c-68$ mutants are defective in some other function of the nervous system that mimics the defect caused by levamisole receptor deficiency. In support of this idea, we find that $u n c-68$

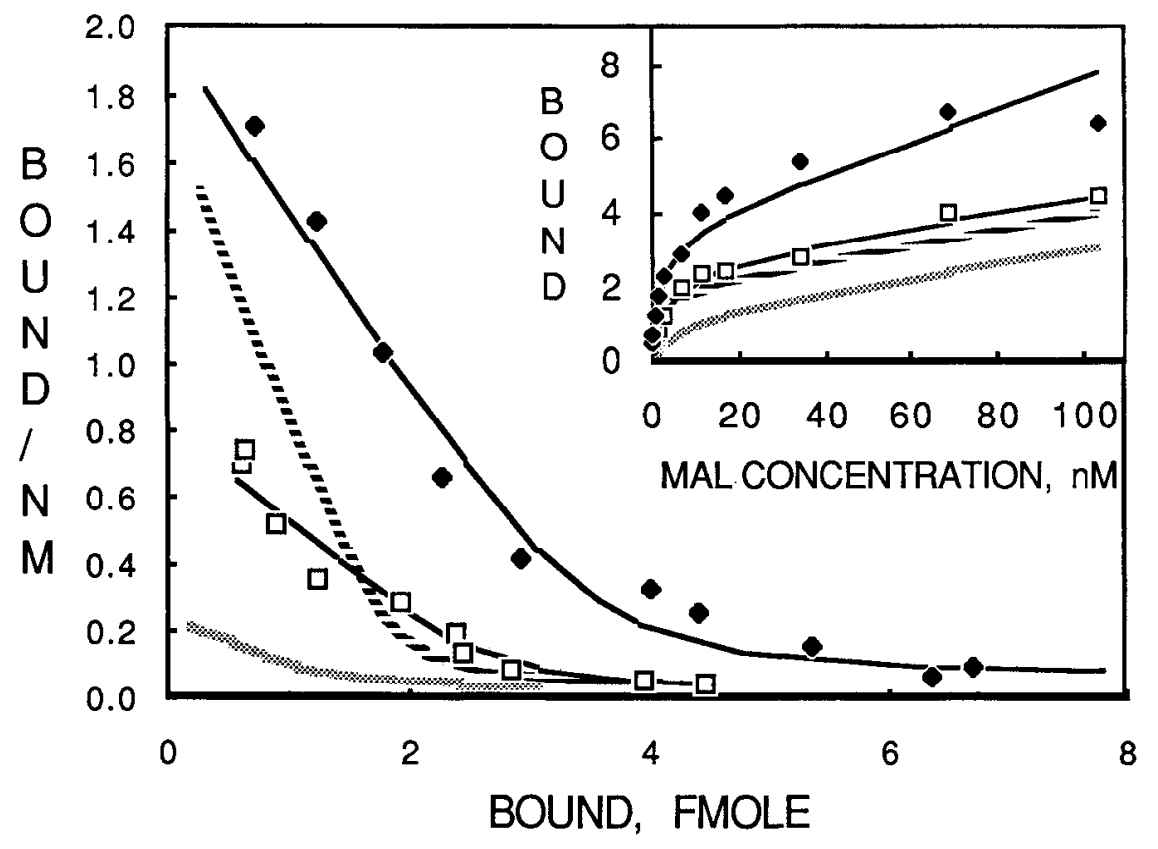

Figure 12. Specific ${ }^{3} \mathrm{H}-\mathrm{MAL}$ binding in an extract of well-fed lev$11(\times 12)$, a mutant with increased total binding (Table 2, no. 22). Binding plotted as for Figure 2. lev$I I(\times 12)$ with $1 \mathrm{~mm}$ mecamylamine, $\checkmark$; with no mecamylamine, 
( $\times 14$ ) has reasonably normal saturable ${ }^{3} \mathrm{H}-\mathrm{MAL}$ binding activity (Table 2 , no. 24).

\section{Discussion}

We have compared the specific ${ }^{3} \mathrm{H}-\mathrm{MAL}$ binding activity present in the wild-type nematode with the binding activities present in levamisole-resistant mutants of 12 different nematode genes. We find the saturable ${ }^{3} \mathrm{H}-\mathrm{MAL}$ binding activity in mutants of 7 of these genes to be clearly abnormal compared to the wild type. These 7 genes are related in that they are all known to produce mutants with a similar stereotyped uncoordinated motor behavior, resistance to levamisole and cholinergic agonists, and sensitivity to hypo-osmotic shock (Lewis et al., 1980b). We conclude from our binding assay results and from the shared phenotype of these mutants that the primary defect in these mutants is levamisole receptor deficiency. The abnormalities detected in binding activity leave no doubt that the receptor activity detected in vitro represents the physiologically relevant site of action for levamisole in vivo.

The mecamylamine effect.has been an important tool in showing the abnormality of binding activity in a number of different mutants. By the simple test of ${ }^{3} \mathrm{H}-\mathrm{MAL}$ binding alone, most mutants, other than those of unc-29, unc-50, and unc-74, would not appear to be greatly different from the wild type. The lack of a mecamylamine effect for mutants of unc-38, unc-63, lev7 , and $l e v-1$ shows that the molecular structure of the levamisole receptor is also altered in these mutants. Mecamylamine probably acts at a second site on the receptor and causes a change in receptor structure that places the ${ }^{3} \mathrm{H}-\mathrm{MAL}$ binding site in a higher-affinity state. The transmittance of this allosteric effect through the receptor probably requires a greater degree of structural integrity than does the simple ability to bind ${ }^{3} \mathrm{H}-\mathrm{MAL}$. The unc-38, unc-63, lev-7, and lev-1 mutants, with no mecamylamine response, have ${ }^{3} \mathrm{H}-\mathrm{MAL}$ binding subunits that cannot be induced to change affinity states.

It is most interesting that a single mutation in any one of 3 different genes (unc-29, unc-50, or $u n c-74$ ) can largely destroy both the high- and low-affinity ${ }^{3} \mathrm{H}-\mathrm{MAL}$ binding sites present in a normal worm. If, as for the vertebrate nicotinic acetylcholine receptor (Conti-Tronconi et al., 1984), sites of differing affinity arise by differential modification of the same polypeptide, a single mutation in the gene encoding the ligand binding subunit could simultaneously destroy the basis for both highand low-affinity ${ }^{3} \mathrm{H}$-MAL ligand binding sites. The $u n c-29$ gene has already been implicated as a good candidate for a gene encoding a ligand binding subunit by rare mutants of the unc29 gene that are very levamisole-resistant, but are still quite responsive to more direct analogs of acetylcholine, and can still move $\sim$ normally (Lewis et al., 1980a). Such rare mutants might be created by site-specific amino acid changes that selectively change the ability of the ligand binding subunit to interact with levamisole without severely affecting the response to more direct acetylcholine analogs or the endogenous receptor signal. The severe deficiency in ${ }^{3} \mathrm{H}-\mathrm{MAL}$ binding that we found in $u n c-29$ mutants further supports the hypothesis that the unc-29 gene encodes a ligand binding subunit. Because severe binding deficiency could arise secondarily from any mutation that causes receptor activity to be unstable and rapidly degraded, firm conclusions as to what any gene does must await higher-resolution molecular studies of the production of individual receptor mRNAs and structural peptides. It is an advantage of our system, however, that any gene that affects receptor production, and not just the receptor structural genes themselves, ought to be detectable by our classical genetic selection for levamisole resistance. Thus, one of the more exciting possibilities for a gene like $u n c-29$, unc-50, or unc-74, which produces little or no receptor activity when mutated, is that when normal, its function is only to indirectly promote or regulate levamisole receptor expression during development, while its mutation halts receptor expression. The opportunity for detecting such gene functions seems inherently greater in our system than in receptor systems based primarily on a biochemical approach to receptor genes through receptor structural peptides and other proteins physically associated with the receptor itself.

Mutants of the $u n c-38, u n c-63, l e v-7$, and $l e v-1$ genes all have substantial amounts of specific ${ }^{3} \mathrm{H}-\mathrm{MAL}$ binding activity, but the activity in these mutants is abnormal, especially in not being activated by mecamylamine. These genes would seem more likely to encode receptor structural peptides other than a ligand binding subunit or to represent functions affecting the maturation and processing of receptor, causing the receptor to end up in an abnormal binding state when a required function is missing. When these mutants are grown as starved worms (Table 3 ), the relative amounts of total high-affinity ${ }^{3} \mathrm{H}-\mathrm{MAL}$ binding appear significantly reduced compared to what is found in the wild type under the same starvation conditions, and to the more normal amounts of high-affinity binding found in these mutants grown as well-fed worms (Table 2). The apparent general decrease in mutant receptor activity in starved worm extracts might be further evidence of receptor structures that are abnormal and undergo some degradation during conditions of growth arrest.

In conclusion, we have identified 7 genes important to the function of a putative nematode muscle acetylcholine receptor. They probably comprise structural genes of the receptor, and might also include functions affecting the receptor's developmental expression or processing. Mutants of several other genes show no distinct receptor abnormality, but might affect receptor function in ways too subtle to detect in our initial screening of well-fed worm extracts, or in ways transcending characterization by ligand binding assay, e.g., receptor placement in the nervous system, or perhaps - as seems more likely for the $u n c-22$ and lev-11 mutants - they might be altered in other functions further along in the process of muscle contraction initiated by levamisole.

Binding assays confirm the importance of a set of genes to receptor function, but only more detailed and direct methods of molecular analysis can determine the actual function of any gene. Two powerful, inherently higher-resolution approaches are now possible. Using affinity columns derivatized with trimethylaminocaprylic acid and concanavalin $\mathrm{A}$, we have copurified both high- and low-affinity binding activities to more than 30,000 times the specific activity present in wild-type crude extracts, and we have raised several monoclonal antibodies against the receptor that reveal at least 2-3 structural peptides in the 40,000 $M_{\mathrm{r}}$ range (J. A. Lewis, S. McLafferty, and J. Skimming, unpublished observations). Transposon tagging (Eide and Anderson, 1985; Greenwald, 1985; Moerman et al., 1986), however, promises to be an even more powerful and more gencral method of analysis. By selection for the occurrence of spontaneous levamisole resistance mutations, we have been able to readily isolate putative Tcl transposon insertions into 6 of the 7 genes that have been identified in this work as affecting receptor binding activity. Beyond those genes already identified, transposon tagging allows for the possibility of cloning almost 
any other gene of the nervous system that can be identified through classical genetics as causing, reverting, or even resembling a receptor-deficient phenotype. Transposon tagging should help circumvent many of the difficulties inherent in this study relating to the low amounts of receptor present and the necessity of indirectly observing mutant phenotypes by binding assay several steps removed from the primary level of gene expression. The ability now to reintroduce cloned genes into nematodes (Fire, 1986) also provides the exciting possibility, since the levamisole receptor is nonessential, of drastically manipulating receptor expression in an in vivo developmental context through deliberate site-directed mutagenesis.

The ability to generate classical genetic mutants might also greatly facilitate the detailed analysis of an $\mathrm{AChR}$ as a protein machine. Partially levamisole-resistant, partially functional receptor mutants likely to be missense amino acid substitutions can easily be obtained using levamisole as a selective agent (Lewis et al., 1980a). Such mutants could be studied in an in vitro or in vivo single-channel assay for their effects on ligand binding, channel opening or closing, ion translocation, etc. Because the muscle cells of adult $C$. elegans hermaphrodites are 10-15 $\mu \mathrm{m}$ across at their widest point (Epstein et al., 1974), direct analysis performed on an in vivo preparation may be possible. Since the precise 3-dimensional structure of membrane receptor molecules is not known, the generation of similar mutants in other systems by site-directed mutagenesis of cloned receptor genes is a very tedious, trial-and-error process. The existence of a phenotypic mutant, however, predefines the DNA sequence change introduced to be of functional importance and more worth the effort of analysis.

\section{References}

Brenner, S. (1974) The genetics of Caenorhabditis elegans. Genetics 77: 71-94.

Changeux, J. P., F. Bon, J. Cartaud, A. Devillers-Thiery, J. Giraudat, T. Heidmann, B. Holton, H.-O. Nghiem, J.-L. Popot, R. Van Rapenbusch, and S. Tzartos (1983) Allosteric properties of the acetylcholine receptor protein from Torpedo marmorata. Cold Spring Harbor Symp. Quant. Biol. 48: 35-52.

Conti-Tronconi, B. M., M. W. Hunkapiller, and M. A. Raftery (1984) Molecular weight and structural nonequivalence of the mature $\alpha$ sub- units of Torpedo californica acetylcholine receptor. Proc. Natl. Acad. Sci. USA 81: 2631-2634.

Draper, N. R., and H. Smith (1981) Applied Regression Analysis, Wiley, New York, p. 110.

Dulley, J. R., and P. A. Grieve (1975) A simple technique for eliminating interference by detergents in the Lowry method of protein determination. Anal. Biochem. 64: 136-141.

Eide, D., and P. Anderson (1985) Transposition of Tcl in the nematode Caenorhabditis elegans. Proc. Natl. Acad. Sci. USA 82: 17561760.

Ellman, G. L., K. D. Courtney, V. Andres, Jr., and R. M. Featherstone (1961) A new and rapid colorimetric determination of acetylcholinesterase activity. Biochem. Pharmacol. 7: 88-95.

Epstein, H. F., R. H. Waterston, and S. Brenner (1974) A mutant affecting the heavy chain of myosin in Caenorhabditis elegans. J. Mol. Biol. 90: 291-300.

Fire, A. (1986) Integrative transformation of Caenorhabditis elegans. EMBO J. 5: 2673-2680.

Greenwald, I. (1985) lin-12, a nematode homeotic gene, is homologous to a set of mammalian proteins that includes epidermal growth factor. Cell 43: 583-590.

Gunst, R. F., and R. L. Mason (1980) Regression Analysis and Its Application, Dekker, New York, p. 256.

Harrow, I. D., and K. A. F. Gration (1985) Mode of action of the anthelmintics morantel, pyrantel and levamisole on muscle cell membrane of the nematode Ascaris suum. Pestic. Sci, 16: 662-672.

Lewis, J. A., and I. Paterson (1984) Preparation of tritium-labelled meta-aminolevamisole of high specific radioactivity by catalytic dehalogenation. J. Lab. Comp. Radiopharmacol. 21: 945-959.

Lewis, J. A., C.-H. Wu, H. Berg, and J. H. Levine (1980a) The genetics of levamisole resistance in the nematode Caenorhabditis elegans. Genetics 95: 905-928.

Lewis, J. A., C.-H. Wu, J.H. Levine, and H. Berg (1980b) Levamisoleresistant mutants of the nematode Caenorhabditis elegans appear to lack pharmacological acetylcholine receptors. Neuroscience 5: 967989.

Lewis, J. A., J. T. Fleming, S. McLafferty, H. Murphy, and C. Wu (1987) The levamisole receptor, a cholinergic receptor of the nematode Caenorhabditis elegans. Mol. Pharmacol. 31: 185-193.

Moerman, D. G., G. M. Benian, and R. H. Waterston (1986) Molecular cloning of the muscle gene unc-22 in Caenorhabditis elegans by $\mathrm{Tcl}$ transposon tagging. Proc. Natl. Acad. Sci. USA 83: 2579-2583.

SAS Institute (1985) SAS User's Guide: Statistics (Version 5 Ed.), SAS Institute, Cary, NC, pp. 575-606.

Waterston, R. H., J. N. Thomson, and S. Brenner (1980) Mutants with altered muscle structure in Caenorhabditis elegans. Dev. Biol. 77: 271-302. 